\title{
Front Matter: Volume 10441
}

"Front Matter: Volume 10441," Proc. SPIE 10441, Counterterrorism, Crime Fighting, Forensics, and Surveillance Technologies, 1044101 (29 November 2017); doi: $10.1117 / 12.2302555$

SPIE. Event: SPIE Security + Defence, 2017, Warsaw, Poland 


\title{
Counterterrorism, Crime Fighting, Forensics, and Surveillance Technologies
}

\author{
Henri Bouma \\ Felicity Carlysle-Davies \\ Robert James Stokes \\ Yitzhak Yitzhaky \\ Editors
}

11-12 September 2017

Warsaw, Poland

Sponsored by

SPIE

Cooperating Organisations

CENSIS: Innovation Centre for Sensor \& Imaging Systems (United Kingdom)

Polish Technological Platform on Photonics (Poland)

MIRPHAB (France)

Photonics Society of Poland (Poland)

Cranfield University (United Kingdom)

Published by

SPIE 
The papers in this volume were part of the technical conference cited on the cover and title page. Papers were selected and subject to review by the editors and conference program committee. Some conference presentations may not be available for publication. Additional papers and presentation recordings may be available online in the SPIE Digital Library at SPIEDigitalLibrary.org.

The papers reflect the work and thoughts of the authors and are published herein as submitted. The publisher is not responsible for the validity of the information or for any outcomes resulting from reliance thereon.

Please use the following format to cite material from these proceedings:

Author(s), "Title of Paper," in Counterterrorism, Crime Fighting, Forensics, and Surveillance Technologies, edited by Henri Bouma, Felicity Carlysle-Davies, Robert James Stokes, Yitzhak Yitzhaky, Proceedings of SPIE Vol. 10441 (SPIE, Bellingham, WA, 2017) Seven-digit Article CID Number.

ISSN: 0277-786X

ISSN: 1996-756X (electronic)

ISBN: 9781510613461

ISBN: 9781510613478 (electronic)

Published by

SPIE

P.O. Box 10, Bellingham, Washington 98227-0010 USA

Telephone +1 3606763290 (Pacific Time) · Fax +1 3606471445

SPIE.org

Copyright (C) 2017, Society of Photo-Optical Instrumentation Engineers.

Copying of material in this book for internal or personal use, or for the internal or personal use of specific clients, beyond the fair use provisions granted by the U.S. Copyright Law is authorized by SPIE subject to payment of copying fees. The Transactional Reporting Service base fee for this volume is $\$ 18.00$ per article (or portion thereof), which should be paid directly to the Copyright Clearance Center (CCC), 222 Rosewood Drive, Danvers, MA 01923. Payment may also be made electronically through CCC Online at copyright.com. Other copying for republication, resale, advertising or promotion, or any form of systematic or multiple reproduction of any material in this book is prohibited except with permission in writing from the publisher. The CCC fee code is 0277$786 \mathrm{X} / 17 / \$ 18.00$.

Printed in the United States of America.

Publication of record for individual papers is online in the SPIE Digital Library.

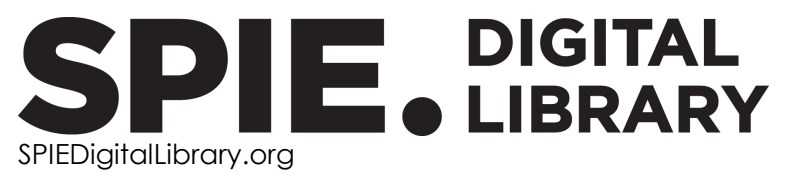

Paper Numbering: Proceedings of SPIE follow an e-First publication model. A unique citation identifier (CID) number is assigned to each article at the time of publication. Utilization of CIDs allows articles to be fully citable as soon as they are published online, and connects the same identifier to all online and print versions of the publication. SPIE uses a seven-digit CID article numbering system structured as follows:

- The first five digits correspond to the SPIE volume number.

- The last two digits indicate publication order within the volume using a Base 36 numbering system employing both numerals and letters. These two-number sets start with 00, 01, 02, 03, $04,05,06,07,08,09,0 A, 0 B \ldots$. OZ, followed by 10-1Z, 20-2Z, etc. The CID Number appears on each page of the manuscript. 


\title{
Contents
}

\author{
$\checkmark \quad$ Authors \\ vii Conference Committee \\ ix Introduction
}

\section{SESSION 1 DETECTION AND IDENTIFICATION OF CBRNE}

$1044102 \mathrm{MMW} / \mathrm{THz}$ imaging using upconversion to visible, based on glow discharge detector array and CCD camera [10441-2]

1044103 Design optimization of Cassegrain telescope for remote explosive trace detection [10441-1]

1044104 Banknote authentication using chaotic elements technology [10441-4]

\section{SESSION 2 SPECTROSCOPY AND RAMAN/LIBS}

1044105 Active vortex sampling system for remote contactless survey of surfaces by laser-based field asymmetrical ion mobility spectrometer [10441-5]

1044106 Raman lidar for remote control explosives in the subway [10441-6]

1044107 New approach for detection and identification of substances using THz TDS [10441-7]

\section{SESSION 3 COMPUTER VISION AND VIDEO CONTENT ANALYSIS}

1044108 Automatically assessing properties of dynamic cameras for camera selection and rapid deployment of video content analysis tasks in large-scale ad-hoc networks [10441-8]

1044109 Face recognition in the thermal infrared domain [10441-9]

10441 OA Three-dimensional measurement system for crime scene documentation (Best Student Paper Award) [10441-10]

\section{SESSION 4 PERSON AND OBJECT DETECTION, TRACKING, AND BEHAVIOR ANALYSIS}

$10441 \mathrm{OB}$ Robust visual object tracking with interleaved segmentation [10441-11]

10441 OC Tracking, aiming, and hitting the UAV with ordinary assault rifle [10441-12] 
10441 OD 3D noise-resistant segmentation and tracking of unknown and occluded objects using integral imaging [10441-13]

\section{SESSION $5 \quad$ BIG DATA ANALYSIS AND DEEP LEARNING}

10441 OF Transferring $x$-ray based automated threat detection between scanners with different energies and resolution [10441-15]

$104410 G$ On the application of semantic technologies to the domain of forensic investigations in financial crimes [10441-16]

$10441 \mathrm{OH} \quad$ Automatic analysis of online image data for law enforcement agencies by concept detection and instance search [10441-17]

10441 Ol Optimizing a neural network for detection of moving vehicles in video [10441-18]

10441 OJ Deep learning-based fine-grained car make/model classification for visual surveillance [10441-19]

\section{SESSION $6 \quad$ AUTONOMOUS SENSORS AND MOBILE ROBOTS}

10441 OK Control system of the inspection robots group applying auctions and multi-criteria analysis for task allocation [10441-20]

$10441 \mathrm{OL} \quad$ Autonomous mobile platform with simultaneous localisation and mapping system for patrolling purposes [10441-21]

10441 ON Autonomous mobile robotic system for supporting counterterrorist and surveillance operations [10441-23]

$1044100 \quad$ Modular robotic system for forensic investigation support [10441-24] 


\title{
Authors
}

Numbers in the index correspond to the last two digits of the seven-digit citation identifier (CID) article numbering system used in Proceedings of SPIE. The first five digits reflect the volume number. Base 36 numbering is employed for the last two digits and indicates the order of articles within the volume. Numbers start with 00, 01, 02, 03, 04, 05, 06, 07, 08, 09, 0A, 0B...0Z, followed by 10-1Z, 20-2Z, etc.

\author{
Abel, Peter, OB \\ Abramovich, Amir, 02 \\ Adamczyk, Marcin, OA \\ Adamczyk, Marek, ON \\ Aharon, Avihai, 02 \\ Akmalov, Artem E., 05 \\ Aloni, Doron, OD \\ Ambadiyil, Sajan, 04 \\ Arens, Michael, OB \\ Baláž, Teodor, OC \\ Becker, Stefan, OB \\ Bhavsar, Kaushalkumar, 03 \\ Bolewicki, Paweł, OA \\ Bouma, Henri, $08, \mathrm{OH}$, Ol \\ Bulandra, Kazimierz, ON \\ Buratowski, Tomasz, OL \\ Burghouts, Gertjan J., 08 \\ Caldwell, M., OF \\ Chistyakov, Alexander A., 05 \\ de Boer, Maaike H. T., OH \\ den Hollander, Richard J. M., 08 \\ Dittmann, Jana, OG \\ Eseller, K. E., 03 \\ Fischer, Noëlle M., $\mathrm{OH}$, Ol \\ Gerlach, Andreas, OG \\ Główka, Jakub, 00 \\ Griffin, L. D., OF \\ Grishkanich, Aleksandr, 06 \\ Grudzień, A., 09 \\ Gundogdu, Erhan, 0J \\ Hagendoorn, Laurens K., $\mathrm{OH}$ \\ Hołowko, Elwira, OA \\ Januszkiewicz, Kamil, OA \\ Joosten, Bart, $\mathrm{OH}$ \\ Jung, Jae-Hyun, OD \\ Kieritz, Hilke, OB \\ Koç, Aykut, OJ \\ Kopeika, Natan S., 02 \\ Kotkovskii, Gennadii E., 05 \\ Kowalski, Grzegorz, 00 \\ Kowalski, M., 09 \\ Krejčí, Jaroslav, OC \\ Kruithof, Maarten $\mathrm{C} ., \mathrm{OH}, \mathrm{Ol}$ \\ Krummel, Volker, OG \\ Lech, Krzysztof, OA \\ Maciaś, Mateusz, 00 \\ Macko, Martin, OC \\ Mączkowski, Grzegorz, OA \\ Mahadevan Pillai, V.P., 04
}

\author{
Merkel, Ronny, OG \\ Michoński, Jakub, OA \\ Mitka, Łukasz, OL \\ Moczulski, Wojciech, OK, ON \\ P.S., Krishnendu, 04 \\ Palka, N., 09 \\ Panfil, Wawrzyniec, OK \\ Parıldı, Enes Sinan, 0J \\ Prabhu, Radhakrishna, 03, 04 \\ Procházka, Stanislav, 0C \\ Puchalski, Sławomir, 00 \\ Raaijmakers, Stephan, $\mathrm{OH}$ \\ Racek, František, OC \\ Ransley, M., OF \\ Redka, Dmitriy, 06 \\ Rogers, T. W., OF \\ Rozban, Daniel, 02 \\ Scheidat, Tobias, OG \\ Sitnik, Robert, OA \\ Solmaz, Berkan, 0J \\ Sychev, Alexei $\vee ., 05$ \\ Szustakowski, M., 09 \\ ten Hove, Johan-Martijn, 08 \\ ter Haar, Frank B., 08, $\mathrm{OH}$ \\ Tishkov, Victor, 06 \\ Trofimov, Vyacheslav A., 07 \\ van Rest, Jeroen H. C., 08 \\ Varentsova, Svetlana A., 07 \\ Vasiliev, Sergey, 06 \\ Weisensee, Michala, OG \\ Yitzhaky, Yitzhak, 02, OD \\ Yücesoy, Veysel, 0J \\ Zagursky, Dmitry Yu., 07 \\ Zakharova, Irina G., 07 \\ Zeihe, Jana, OG \\ Zhevlakov, Aleksandr, 06
}


Proc. of SPIE Vol. 10441 1044101-6

Downloaded From: https://www.spiedigitallibrary.org/conference-proceedings-of-spie on 25 Apr 2023 Terms of Use: https://www.spiedigitallibrary.org/terms-of-use 


\section{Conference Committee}

Symposium Chair

Ric Schleijpen, TNO Defence, Security and Safety (Netherlands)

Symposium Co-Chairs

Karin Stein, Fraunhofer Institute of Optronics, System Technologies and Image Exploitation IOSB (Germany)

Jan K. Jabczyński, Military University of Technology (Poland)

Conference Chairs

Henri Bouma, TNO (Netherlands)

Felicity Carlysle-Davies, Forensic Science SIG KTN (United Kingdom)

Robert James Stokes, Cobalt Light Systems Ltd. (United Kingdom)

Yitzhak Yitzhaky, Ben-Gurion University of the Negev (Israel)

Conference Program Committee

Maria Andersson, FOl-Swedish Defence Research Agency (Sweden)

Stefan Becker, Fraunhofer-Institut für Optronik, Systemtechnik und Bildauswertung (Germany)

Brian E. Foulger, Ministry of Defence (United Kingdom)

Pengda Hong, Lehigh University (United States)

Gillian F. Marshall, QinetiQ Ltd. (United Kingdom)

David Muench, Fraunhofer-Institut für Optronik, Systemtechnik und Bildauswertung (Germany)

Niamh Nic Daeid, University of Dundee (United Kingdom)

Radhakrishna Prabhu, The Robert Gordon University (United Kingdom)

Salman Rosenwaks, Ben-Gurion University of the Negev (Israel)

Neil C. Shand, Defence Science and Technology Laboratory (United Kingdom)

Piotr Szynkarczyk, Industrial Research Institute for Automation and Measurements (Poland)

Paul A. Thomas, Defence Science and Technology Laboratory (United Kingdom) 


\section{Session Chairs}

1 Detection and Identification of CBRNE

Felicity Carlysle-Davies, The Knowledge Transfer Network Ltd.

(United Kingdom)

Robert James Stokes, Cobalt Light Systems Ltd. (United Kingdom)

2 Spectroscopy and Raman/LIBS

Felicity Carlysle-Davies, The Knowledge Transfer Network Ltd. (United Kingdom)

Robert James Stokes, Cobalt Light Systems Ltd. (United Kingdom)

3 Computer Vision and Video Content Analysis

Henri Bouma, TNO (Netherlands)

Yitzhak Yitzhaky, Ben-Gurion University of the Negev (Israel)

4 Person and Object Detection, Tracking, and Behavior Analysis

Henri Bouma, TNO (Netherlands)

Yitzhak Yitzhaky, Ben-Gurion University of the Negev (Israel)

$5 \quad$ Big Data Analysis and Deep Learning

Henri Bouma, TNO (Netherlands)

Yitzhak Yitzhaky, Ben-Gurion University of the Negev (Israel)

6 Autonomous Sensors and Mobile Robots

Piotr Szynkarczyk, Industrial Research Institute for Automation and Measurements (Poland) 


\section{Introduction}

The Counterterrorism, Crime Fighting, Forensics and Surveillance conference held 11-12 September 2017 in Warsaw, Poland, brought together emerging technologies for countering terrorism and crime and providing support to forensics, surveillance, security and defence forces. The conference addressed the big issue of maintaining security and safety by detecting and identifying dangerous, hidden, and camouflaged materials and recognizing suspicious behaviour from video imagery, all the while working within a legal and moral framework that respects individuals' rights.

Sensors for explosives, narcotics, and chemical and biological warfare agents must provide a prompt alert with fast, wide area coverage and must cope with unexpected hiding places. If they are to be routinely deployed, such sensors must offer accurate detection and low false alarm rates, use few consumables, and need little operator involvement. Optical sensing now extends from UV, through visible and infrared, into terahertz and RF wavelengths, offering novel imaging systems with increased penetration through barriers, and spectroscopic techniques that can help characterize suspicious materials.

The threat from people's activities can be reduced by identifying suspicious behaviour and by tracking individuals across multiple TV cameras. Increased computing power and advanced algorithms are expected to help in difficult scenarios such as crowded environments (face and iris recognition or other biometrics), and longer range imagery through turbulent atmospheres. Improved handover techniques from TV imaging will reduce the burden placed on local sensors.

The first session of this conference focused on the detection and identification of CBRNE. The first presentation showed an inexpensive method for upconversion of $\mathrm{MMW} / \mathrm{THz}$ imaging that is based on a glow discharge detector (GDD) and silicon photodiode or simple CCD/CMOS camera [Aharon et al.]. The second presentation showed a standoff LIBS-based method to remotely detect explosive traces from several to tens of metres distance. A Cassegrain telescope was used to make the LIBS system more compact and a Schmidt corrector plate was used to eliminate spherical aberrations [Bhavsar et al.]. The third presentation aimed to avoid counterfeit banknotes by adding chaotic elements based on fibres in the paper pulp. The fibres result in a unique ID and a related QR code is printed on the banknote during the production. The authenticity of the banknote should be verifiable by any person who receives the note [Prabhu et al.].

The second session was on spectroscopy and Raman/LIBS. The first presentation in the session showed that rotating impeller increases allows the detection of traces of explosives at a larger distance than with existing systems based on fixed impeller 
[Kotkovskii et al.]. In the second paper of the session was on a Raman lidar that was designed for remote detection of more than 4000 Raman shifts of various chemical, toxic or dangerous substances, explosives, and drugs [Grishkanich et al.]. The last paper of this session proposed a new approach for the detection and identification of substances using a THz TDS [Trofimov et al.].

The third session was on computer vision and video content analysis. The first presentation in this session proposed to use the terminology of managed analytics and makes a separation between primary (e.g., aggression detection) and supporting analytics (e.g., PTZ-preset recognition) [Den Hollander et al.]. The second presentation showed face verification in infrared images [Kowalski et al.]. The third presentation showed a system to generate a three-dimensional pointcloud model that can be used to create an overview of a crime scene. This overview model can be combined with details recordings about blood stains and it supports automatic blood stain analysis [Adamczyk et al.]. The best student paper prize was awarded to this last presenter of the session, Marcin Adamczyk, who is a PhD student at the Warsaw University of Technology.

The fourth session was about person and object detection, tracking and behaviour analysis. The first presentation of this session is about robust visual object tracking. The initial tracker is extended by enabling the use of rotated rectangles as tracking states. The fixed aspect-ratio assumption is dissolved by constructing a confidence map from the on-line boosting-based tracker [Becker et al.]. The second presentation showed the subjective and objective factors that influence the error in aiming a rifle at a UAV. Experimental measurements and theoretical analysis with Monte Carlo simulations were shown [Racek et al.]. The third presentation used 3D object segmentation for tracking, based on an integral imaging system with an array of lenses or cameras [Aloni et al.].

The fifth session was on big data analysis and deep learning. The first presentation used a CNN to detect threats in x-ray cargo scanners. Transfer learning and fine tuning is used to generalize better for multiple scanners [Caldwell et al.]. The second presentation used semantic technologies for forensic investigations in financial crimes. The technology helps the investigator to find relations between different case entities and relations to other cases. The crime field ontology is based on knowledge obtained from online search, forensic investigators, and captive interviews of detained criminals [Scheidat et al.]. The third presentation showed results of the concept detection with SSD and instance search with Fisher vectors on the datasets of VOC2012 and FlickrLogos [De Boer et al.]. The fourth presentation combined the end-to-end convolutional neural network (YOLO) with a recurrent neural network (LSTM) for multi-frame analysis to perform vehicle tracking [Fischer et al.]. The last presentation of this session used AlexNet to distinguish not only car makes, but even the different models within that make.

The last session was chaired by Prof. Piotr Szynkarczyk from the Industrial Research Institute for Automation and Measurements in Poland. Dr. Szynkarczyk also 
contributed in the creation of this session. The session focused on autonomous sensors and mobile robots. The first presentation of the session was on auctions and multi-criteria analysis for task allocation a group of inspection robots [Panfil et al.]. The second presentation was about simultaneous localization and mapping (SLAM) to estimate the position of a mobile platform and generate a 3D point cloud to describe the scene [Mitka et al.]. The third presentation gave an overview of the capabilities of a mobile robot developed by PIAP that could be used for forensic investigations on crime scenes [Kowalski et al.]. And finally, the last presentation presented a security system for counterterrorism and surveillance applications with stationary radars, mobile radars and an intervention robot with an acoustic gun. This session summarized a wide range of several possibilities with mobile robots [Moczulski et al.].

\section{Henri Bouma Felicity Carlysle-Davies Robert James Stokes Yitzhak Yitzhaky}


Proc. of SPIE Vol. 10441 1044101-12 Downloaded From: https://www.spiedigitallibrary.org/conference-proceedings-of-spie on 25 Apr 2023
Terms of Use: https://www.spiedigitallibrary.org/terms-of-use 